\title{
The influence of particle shape and mineralogy on the particle strength, breakage and compressibility
}

\author{
Xiaoyan Zhang ${ }^{1 *}\left(\mathbb{0}\right.$, Beatrice A. Baudet ${ }^{2}$ and Ting Yao ${ }^{3}$
}

\author{
*Correspondence: \\ zhangxiaoyan@cumtb.edu.cn \\ ${ }^{1}$ China University of Mining \\ and Technology, Ding No. \\ 11 Xueyuan Road, Haidian \\ District, Beijing, China \\ Full list of author information \\ is available at the end of the \\ article
}

\begin{abstract}
It is widely accepted that both particle shape and mineralogy could have a great effect on the particle strength. However, due to the complexity of nature grains, it is difficult to distinguish the influence of particle shape from mineralogy. This paper shows measurements of the particle shape and mineralogy of carbonate sand, completely decomposed granite, Leighton Buzzard sand and pumice sand. The particle shape of carbonate sand and completely decomposed granite is similar, but the mineral of carbonate sand is carbon dioxide while the mineral of completely decomposed granite is mica and feldspar. It is found that the single particle strength of completely decomposed granite is higher than that of carbonate sand, and the particle breakage caused by one-dimensional compressing tests of completely decomposed granite is higher than that of carbonate sand. The mineralogy of both completely decomposed granite and Leighton Buzzard sand are quartz, but completely decomposed granite is more heterogeneous, result in the single particle strength of completely decomposed granite is much lower than that of Leighton Buzzard sand. It is also found the particle breakage from the one-dimensional compression test for completely decomposed is larger than Leighton Buzzard sand. It should be noted that carbonate sand is stronger than completely decomposed granite after quantitatively analysis the particle shape, particle breakage and compressibility behavior although carbonate sand has extremely irregular shape such as a branch shape, and also several pores. On the other hand, although Leighton Buzzard sand, completely decomposed granite and also pumice sand to some extent have composition of silica, the crystal of those three is completely different, result in the strength or compressibility are quite different. It seems that particle shape is not a major factor to affect strength or compressibility, but the mineralogy could be a major factor.
\end{abstract}

Keywords: Particle shape, Single particle crushing strength, Breakage, Compressibility, Mineralogy

\section{Introduction}

Particle breakage plays an important role in determining the constitutive relation for granular materials at high or medium high stress. For one-dimensional compression, the slope of normal compression line and the plastic deformation were found to significantly affected by the particle breakage $[1,21,23,24,29]$. Constitutive relation incorporated 
with particle breakage was developed theoretically for one-dimensional compression [5], tri-axial conditions [14, 16, 17, 28, 34]. McDowell [20] suggested that macroscopic yielding stress dominated by the average tensile strength. Single particle crushing tests were carried out to determine average tensile strength on a wide range of size of grains and verity of minerals $[7,20,30,41]$. This finding provides valuable information for calibration of crushable particle during discrete-element method modelling [10, 25, 26]. Physical test and numerical simulations have been used to understand the load-deformation behavior of individual particle or the stress-strain response under macro stress. However, limited studies were carried out to study the role of fundamental parameters on single-particle fracture or stress-strain response.

Particle size distribution, particle shape and mineralogy are basic fundamental parameters used to describe of sands. Image based methods were used to quantify particle shape in geomechanics and geology, for example, roundness [33, 36], sphericity [11, 27]. Particle shape has a great effect on the mechanical properties of sand, for example, the relative density [11, 27], stiffness [11], breakage [4, 35] and mechanical behavior [3]. Although particle shape for 36 kinds of sands was investigated by Altuhafi et al. [2], they have not studied the effects of shapes on mechanical behavior. Besides, due to the practical problems, behavior of different mineralogy sand, such as crushable carbonate sand $[7,12,13,40]$, volcanic ash [19] and tailing sand $[6,8,9]$ have been studied in recent decades. Since the complex of nature sand, the contribution of the particle shape or mineralogy on mechanical behavior is not easy to distinguish. Thus, this paper focus on investigating the influence of particle shape and mineralogy on average tensile strength, particle breakage and compressibility. Four widely used sands, such as weathered completely decomposed granite (CDG), carbonate sand (CS), Leighton Buzzard sand (LBS) and nature volcanic eruption deposit pumice sand (PM) were used in this paper for comparison.

\section{Test materials and methods}

Four kinds of material were used in this study, including completely decomposed granite (CDG), carbonate sand (CS), standard Leighton Buzzard sand (LBS) and pumice deposits (PM). Figure 1 shows an example of Leica microscope image and Fig. 2 shows scanning electron microscope (SEM) image (Hitachi S3400N VP scanning electron microscope) for CDG, CS, LBS and PM with grain size of 0.6-1.18 mm and 1.18-2.0 mm (mechanical sieved following British standard BS1377-2:1990). An advanced particle size analysis and shape evaluation apparatus (QicPic made by a Germany company SYMPATEC) was applied to measure shape of each material. Two main shape factor, aspect ratio (AR) and sphericity was applied in this paper to describe shape of particles. Aspect ratio is a ratio of Feret ${ }_{\min }$ over Feret $_{\max }$. Feret ${ }_{\min }$ or Feret $_{\max }$ is the minimum or maximum distances between two parallel tangents lines around the particle. Sphericity is a parameter described degree of similarity between a particle to a sphere [2], which is the ratio of equivalent perimeter of a circle with equivalent area with projected area to real perimeter of a projected particle. Thus, AR could be a parameter to represent the irregular shape of particle while sphericity could be a parameter to represent how smooth or roughness of particle. 

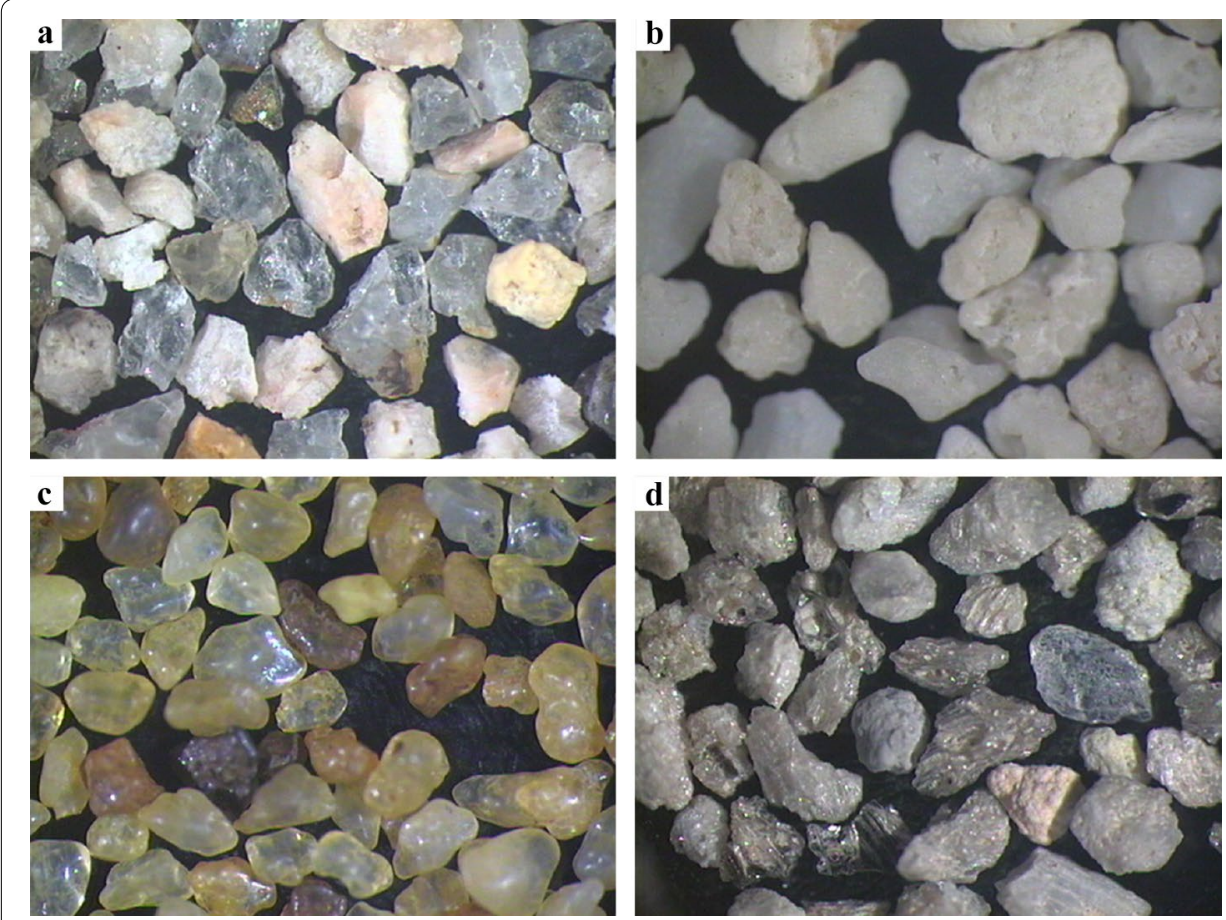

Fig. 1 Microscope images for test materials with size of 0.6-1.18 mm: a completely decomposed granite; $\mathbf{b}$ carbonate sand; $\mathbf{c}$ Leighton Buzzard sand; $\mathbf{d}$ pumice sand
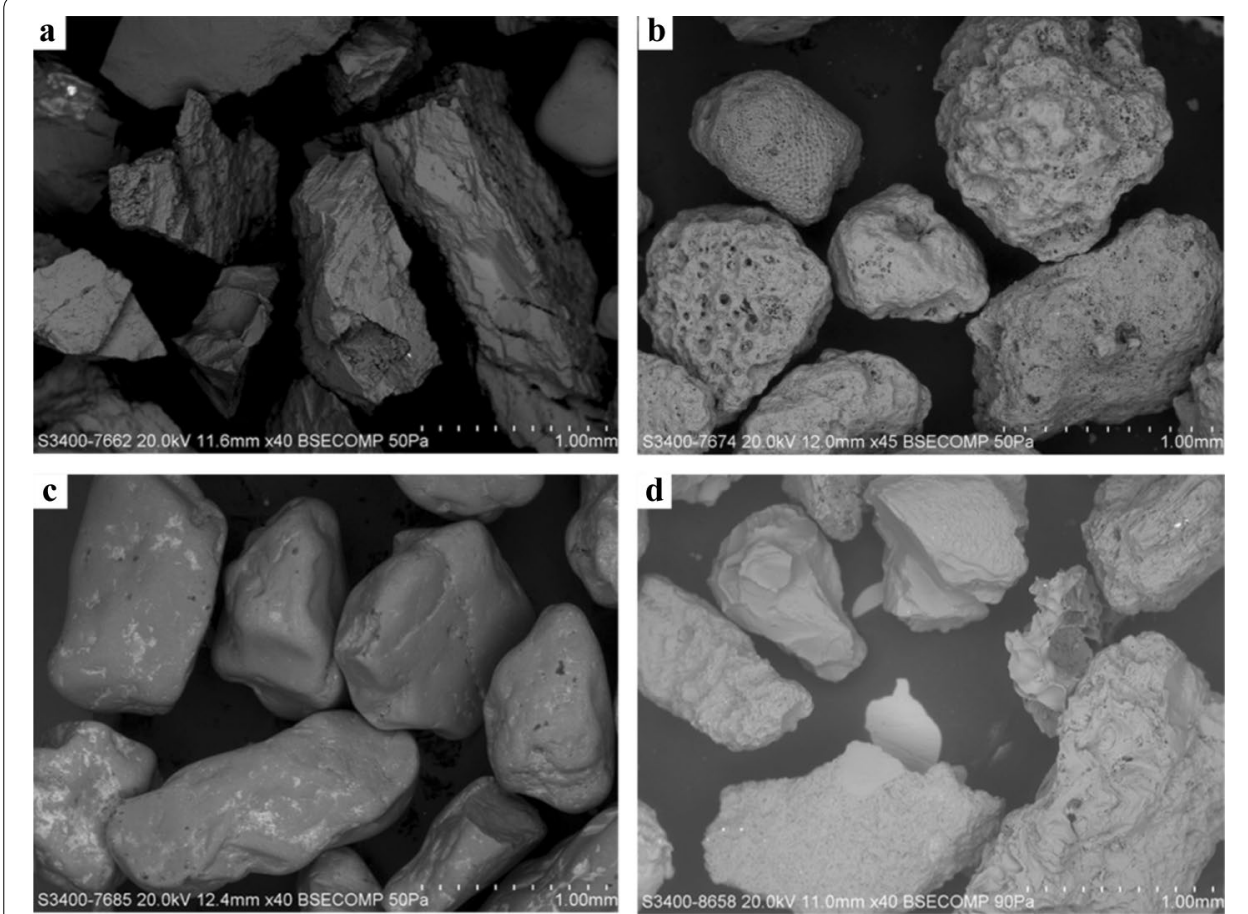

Fig. 2 Scanning electron microscope images for test materials with size of $0.6-1.18 \mathrm{~mm}$ : a completely decomposed granite; $\mathbf{b}$ carbonate sand; $\mathbf{c}$ Leighton Buzzard sand; $\mathbf{d}$ pumice sand 
CDG is the product of old Hong Kong granite rock that has weathered into soil particles ranging in size from coarse sand to silt. The mineralogy of the soil grains consists of mica and feldspar, and it is not difficult to distinguish these two different components from Fig. 1. The Mica looks transparent, is monoclinic and has perfect cleavage as a result of its atoms being arranged of hexagonal sheet like. Mica and Feldspar were picked out to determine the mineral elements by spectrum processing separately. Figure 3 shows scanning electron microscope images for Completely decomposed granite with mineral compositions of feldspar and mica at magnitude of $200 \times$. The mineral elements of Mica are predominantly Si and $\mathrm{O}$, and include a small amount of $\mathrm{K}, \mathrm{Na}, \mathrm{Al}$ and $\mathrm{Fe}$ to formal group of silicate minerals. Feldspar is a group of rock-forming tectosilicate minerals and it was found to be majorly $\mathrm{KAlSi}_{3} \mathrm{O}_{8}$ and $\mathrm{NaAlSi}_{3} \mathrm{O}_{8}$.

CS examined in this study comes from South China sea is the product of corals, mollusc shells and algae, and the mineral components are $\mathrm{Ca}, \mathrm{C}$ and $\mathrm{O}$ predominantly (98.13\%) [13], with negligible quantities of, $\mathrm{Na}, \mathrm{Mg}, \mathrm{Al}$ and $\mathrm{S}$. LBS is rounded and mainly quartztic. It is found that LBS does not only include $\mathrm{Si}$, O, but also a small amount of $\mathrm{C}, \mathrm{Fe}$ and $\mathrm{K}$ which could be due to impurities attached on the surface. Pumice (PM) deposits are a light, porous volcanic rock that generated from the explose of the eruptions when the lava is permeated with gas bubbles during the solidification process, resulting in pumice deposits being characterized by the vesicular material. The mineralogy components are majorly $71.0 \%$ silica, $13.0 \%$ aluminum oxide and $2.0 \%$ ferric oxide [32].

The single particle crushing tests were carried out on the apparatus used for unconfined compression test suggested by Mcdowell and Amon [22]. The top platen is fixed and the bottom platen moves up. The force $F$ applied to the grains is measured by the proving ring dial gauge and the stress applied to the particles is computed as Eq. (1):

$$
\sigma=\frac{F}{d}
$$

where $d$ is the diameter of particle and the unit is $\mathrm{mm}$. The load measuring capacity of the device is $10 \mathrm{kN}$ with a resolution of $0.001 \mathrm{~N}$, and the resolution of displacement measuring is $0.1 \mathrm{~mm}$. The loading rate is $0.1 \mathrm{~mm} / \mathrm{s}$ suggested by Nakata et al. [30]. Weibull [37] suggested that the probability $P$ of choosing at random an individual have a $X$ equal to or less than $\mathrm{x}$, and could have
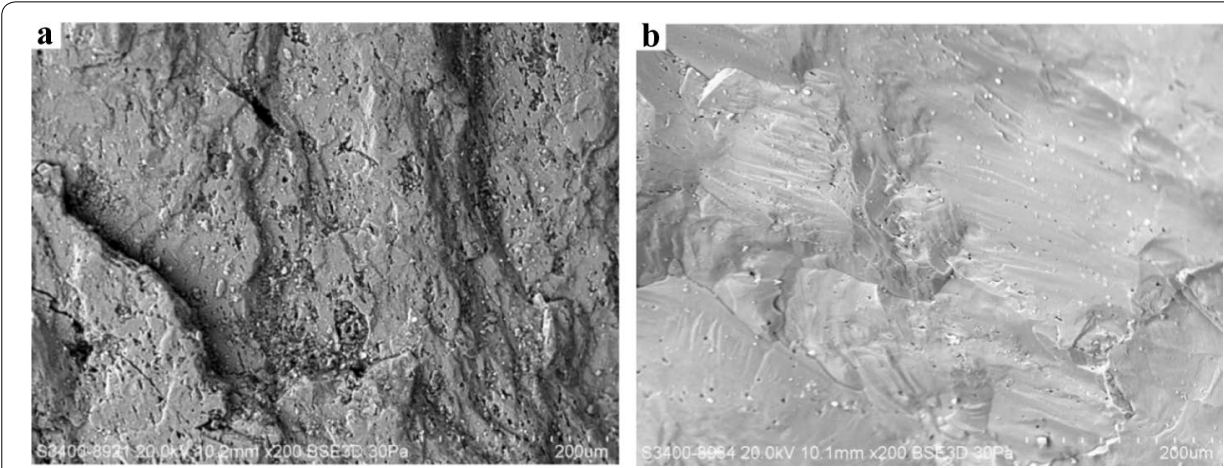

Fig. 3 Scanning electron microscope images for completely decomposed granite with size of $0.6-1.18 \mathrm{~mm}$ at magnification of $\times 200$ : $\mathbf{a}$ feldspar; $\mathbf{b}$ mica 


$$
P(X \leq x)=F(x)
$$

He also considered that any distribution may be written in the form:

$$
F(x)=1-e^{-\varphi(x)}
$$

Thus, for a great number of individual $n$, the probability of failure is $P_{n}$ while the probability of nonfailure $\left(1-P_{n}\right)$ is equal to the probability of the simultaneous non failure of all $\left(1-P_{n}\right)=(1-P)^{n}$. Thus, the survival probability $P_{s}$ of a volume $V_{0}$ under a uniform tensile stress $\sigma$ is given by:

$$
P_{s}\left(V_{0}\right)=1-P_{n}=\exp \left[-\left(\frac{\sigma}{\sigma_{0}}\right)^{m}\right]
$$

where if the stress $\sigma=\sigma_{0}, P_{s}\left(V_{0}\right)$ is equal to $37 \%$, and thus $\sigma_{0}$ is the stress for $37 \%$ of tested specimens survive, and $\mathrm{m}$ is Weibull modulus.

The procedure of one-dimensional consolidation tests followed the British standard (BS 1377-5:1990). The specimens were prepared by dry deposition, then tamping into an initial pre-set height, and all the tests are carried out under dry condition. The initial void ratio was calculated using three different methods relying on independent measurements [1], for which the difference in void ratios was found to be within \pm 0.01 . The final grading was estimated after each test by mechanical dry sieving.

\section{Results}

Figure 4 shows the particle shape distribution, which present the cumulative percentage passing by volume across the entirety of shape factors. CS as a product of corals, mollusc shells and algae was considered as a very irregular and fragile material like Dog's Bay sand $[12,15,31]$, or contains several intra-voids [38], but it is surprising to note that $\mathrm{AR}_{50}$ of CDG is smallest among four kinds of materials, which indicate that CDG could be the most irregular material instead of CS from statistic quantification. LBS as a British standard quartz sand is rounded, where the line for AR in Fig. 3a located in the rightmost. From Fig. 3b, sphericity distribution of CDG, CS and PM are very close, while that of LBS is far right from those three materials, because the surface of LBS is very smooth as shown in Fig. 1. Thus, LBS is a regular shape grains, while CDG is the most irregular shape grains instead of the CS among four sands.

Figure 5 shows the Weibull modulus and the 37\% survival possibility strength of CDG. Mica and feldspar within CDG were measured separately by single particle crushing tests, and it was found that the $37 \%$ survival possibility strength of mica with size of 0.6-1.18 $\mathrm{mm}$ is 94.8 MPa, while that of feldspar is 38.1 MPa. For CDG with size of 1.18$2.0 \mathrm{~mm}$, the $37 \%$ survival possibility strength of mica is $79.5 \mathrm{MPa}$, while that of feldspar is 16.8 MPa as shown in Table 1. This is in a good agreement with Mcdowell and Amon [22] that the $37 \%$ survival possibility strength is decreasing with the increase of size of particle because the large particle could include more defects. It seems that the tensile strength of feldspar is much lower than that of mica. Zhao et al. [41] found that feldspar includes fractures caused the failure of feldspar along with the crystallographic planes, where has a very low bonding stress. Although PM include $71 \%$ of silica, average tensile 

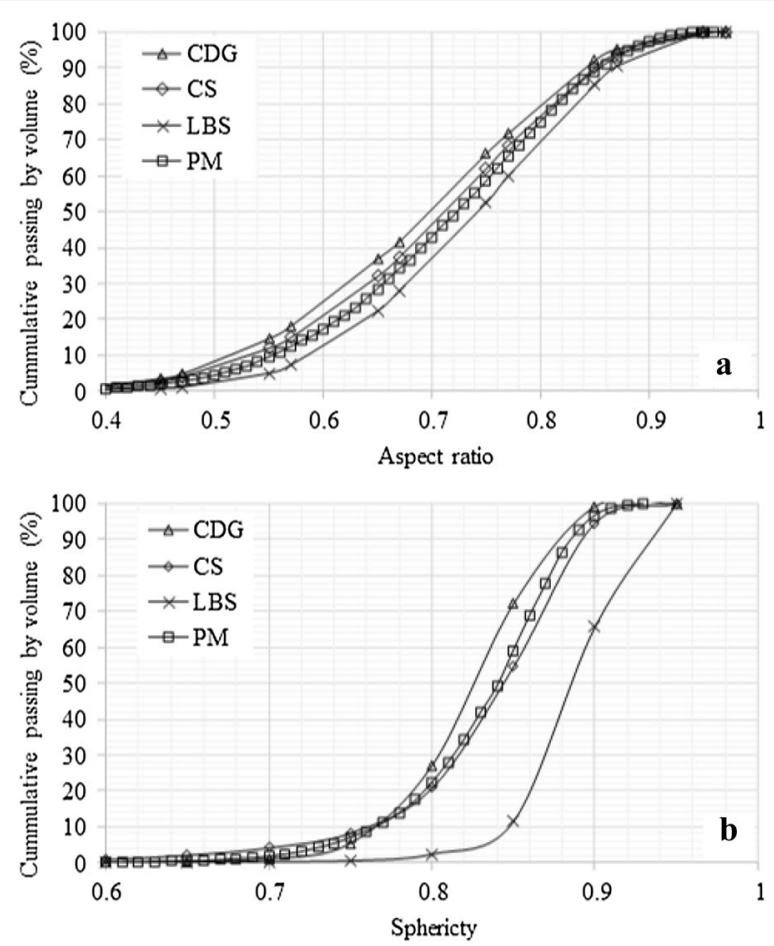

Fig. 4 Shape distribution: $\mathbf{a}$ aspect ratio; $\mathbf{b}$ sphericity

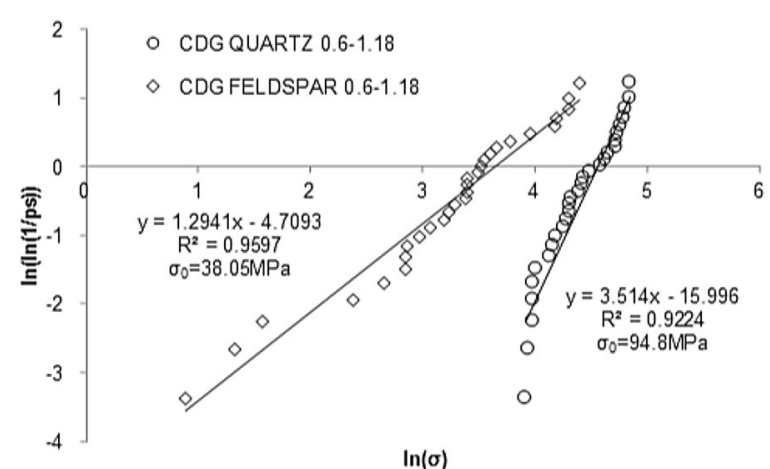

Fig. 5 The 37\% survival possibility strength of CDG

Table 1 Shape factors for test materials and the $37 \%$ average tensile strength $\left(\sigma_{0}\right)$ measured by single particle crushing tests

\begin{tabular}{llllll}
\hline Test material & Size $(\mathbf{m m})$ & $\mathbf{d}_{\mathbf{5 0}}^{\text {Fmin }}(\mathbf{m m})$ & $\mathbf{A R}_{\mathbf{5 0}}$ & $\mathbf{S}_{\mathbf{5 0}}$ & $\mathbf{\sigma}_{\mathbf{0}}(\mathbf{M P a})$ \\
\hline CDG & $1.18-2$ & 1.805 & 0.715 & 0.830 & 16.8 \\
& $0.6-1.18$ & 1.028 & 0.698 & 0.828 & 38.1 \\
CS & $1.18-2$ & 1.633 & 0.715 & 0.845 & 30.4 \\
& $0.6-1.18$ & 0.949 & 0.712 & 0.845 & 41.5 \\
LBS & $1.18-2$ & 1.745 & 0.762 & 0.894 & 41.7 \\
& $0.6-1.18$ & 0.878 & 0.741 & 0.891 & 66.7 \\
PM & $0.6-1.18$ & 1.035 & 0.724 & 0.841 & 30.4 \\
\hline
\end{tabular}


strength of PM is $31.92 \mathrm{MPa}$ shown in Fig. 6b, which is even less than that of feldspar, this could because PM includes a great number of intra-voids caused the structure of PM like a honeycomb. It is well known that CS includes several intra-voids as well [12], but the $37 \%$ survival possibility strength of CS is $41.5 \mathrm{MPa}$, which is much higher than that of PM. It seems that intra-voids within PM is far more than that of CS, because the specific gravity of PM is 2.28 while the specific gravity of CS is 2.75 .

Figure 6 shows the relationship between the void ratio and logarithm effective vertical stress among four sands under one-dimensional compression tests. It should be noted that it is impossible to prepare the same initial void ratio specimen due to the minimum void ratio among four sands are quite different. Here the yielding stress has been taken to be the point of maximum curvature on the $e-\log \sigma_{0}$, which are approximately $5 \mathrm{MPa}$, $9 \mathrm{MPa}, 11 \mathrm{MPa}$ and $15 \mathrm{MPa}$ for PM, CS, CDG and LBS, respectively, and the yielding stress could be four times less than the $37 \%$ survival possibility strength suggested by McDowell [20]. This seems to indicate that the strength of four sands are in order of PM, CS, CDG and LBS. Although average tensile strength of mica in CDG is highest, a great number of feldspar in CDG caused the yielding stress of CDG is smaller than that of LBS. The yielding stress of CDG depends on the tensile strength of feldspar instead of mica because the yielding strength dominated by the weakest grains in a specimen.

Figure $7 \mathrm{~b}$ shows particle size distribution after one-dimensional compression at a stress of $18 \mathrm{MPa}$. The relative breakage $(\mathrm{Br})$ was calculated by using Hardin's method [18]. Br of CDG, CS, LBS and PM are 0.335, 0.217, 0.067 and 0.487 respectively. PM suffered the largest particle breakage, while breakage of CS and CDG are quite close.
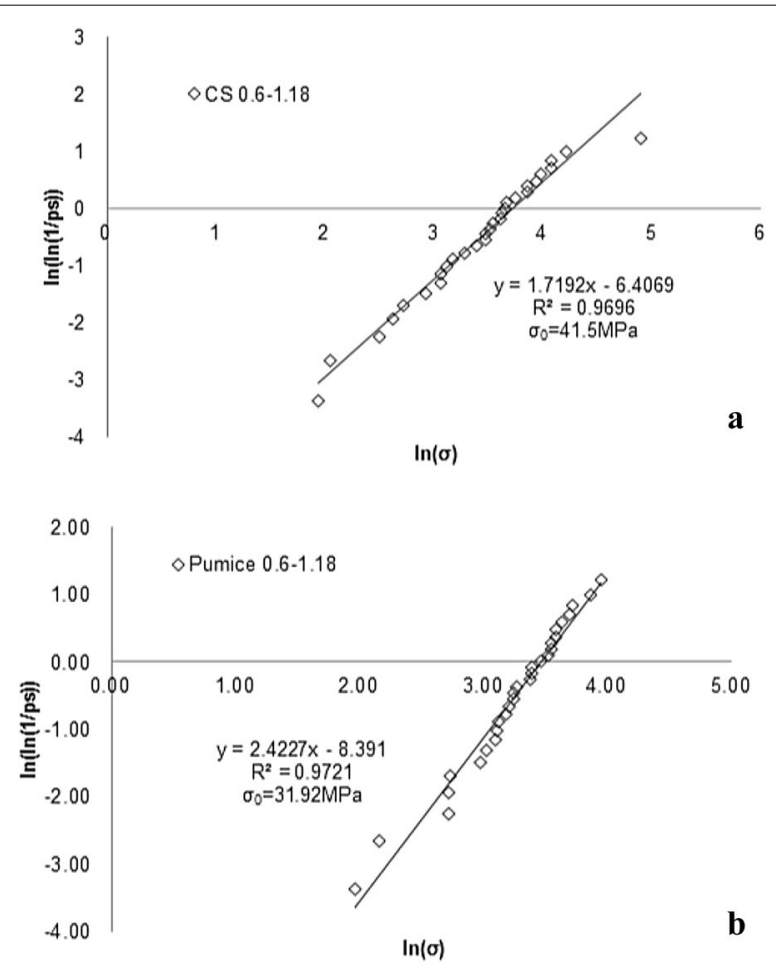

Fig. 6 The 37\% survival possibility strength of CS and PM 

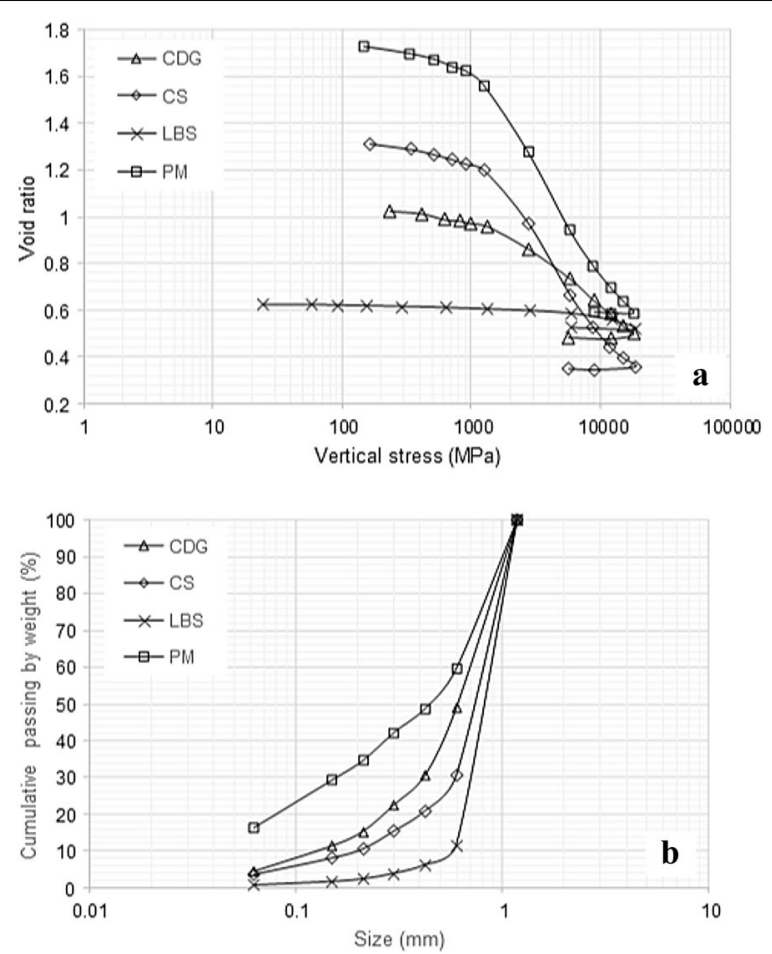

Fig. 7 Experimental results for one-dimensional compression tests of four sands: a the void ratio against logarithm effective vertical stress; $\mathbf{b}$ particle size distribution curves

Breakage of LBS is far less than that of other three sands, even the $37 \%$ survival possibility strength of LBS is 66.7 MPa suggested by McDowell [20], which is far less than 94.8 MPa of mica within CDG. Particle breakage also depends on the strength of weakest sands. Zhang and Baudet [39] found the breakage in gap-graded soils depends on the size of large particle, nor the ratio of large to small size of particle. This could be the same reason that particle breakage is dominated by the weakest particle, where tensile strength of larger size particle in the same ratio gap-graded soil is less than that of smaller size of large particle.

\section{Discussions}

Particle shape, mineralogy and texture seem to have a mutual effect on the strength, particle breakage and compressibility among four sands. The mineral compositions of PM, CDG and LBS are majorly silica and the contents of silica in CDG, PM and LBS are approximately $40 \%, 70 \%$ and $90 \%$. However, the $37 \%$ survival possibility strength and yielding stress of CDG lies between PM and LBS. It seems that the mineral composition plays a minor role in the $37 \%$ survival possibility strength, yielding stress and particle breakage.

It is worth noticing that regular LBS has the highest $\mathrm{AR}_{50}$ and $\mathrm{S}_{50}$, and the $37 \%$ survival possibility strength, yielding stress and particle breakage also reach the maximum value among four sands. In compare to $\mathrm{AR}_{50}$ and $\mathrm{S}_{50}$ of CDG and CS, CDG seems to be more angular than CS through quantitatively analysis, result in the $37 \%$ survival possibility strength and yielding stress of CDG is slightly lower than those of CS, result in $\mathrm{Br}$ 
of CS is lower than that of CDG under the same compression stress, even CS includes a greater number of intro-voids. It seems that particle shape influences on the $37 \%$ survival possibility strength and yielding stress. Apart from mineralogy and particle shape, it was found that the $37 \%$ survival possibility strength and yielding stress of CS is greater than that of PM due to the significantly greater number of intro-voids of PM irrespective to the mineralogy and shape, although $\mathrm{AR}_{50}$ and $\mathrm{S}_{50}$ of CS is similar with that of PM and both particles have honeycomb structure.

\section{Conclusions}

Sands from a variety of origins, CDG, CS, LBS and PM, were examined through shape analysis, single particle crushing tests and one-dimensional compression tests. It was found mineralogy plays a minor role, but the particle shape seems to have an influence on $37 \%$ survival possibility, yielding stress and particle breakage. Besides, the texture of particle seems also important, and the weakest mineral of particle could become dominant the strength when particle with mixed mineralogy.

\section{Acknowledgements}

This research was supported by the National Science Foundation for Young Scientists of China (Grant No. 51809264), the State Key Laboratory of Geo-Hazard Prevention and Geo-environmental Protection of Chengdu University of Technology (SKLGP2018K024), Fundamental Research Funds for the Central Universities (2017QL04).

\section{Authors' contributions}

$X Z$ carried out the one-dimensional compression tests and the measurement for minerology, while TY carried out the single particle crushing tests. XZ drafted this manuscript, and BAB gave valuable suggestions and correction. All authors read and approved the final manuscript.

\section{Competing interests}

The authors declare that they have no competing interests.

\section{Author details}

${ }^{1}$ China University of Mining and Technology, Ding No. 11 Xueyuan Road, Haidian District, Beijing, China. ${ }^{2}$ University College London, London, UK. ${ }^{3}$ Chinese Academy of Science, Wuhan, China.

Received: 11 December 2018 Accepted: 24 January 2020

Published online: 05 February 2020

\section{References}

1. Altuhafi F, Coop M (2011) Changes to particle characteristics associated with the compression of sands. Géotechnique 61(6):459-471

2. Altuhafi F, O'sullivan C, Cavarretta I (2013) Analysis of an image-based method to quantify the size and shape of sand particles. J Geotech Geoenviron Eng 139(8):1290-1307

3. Altuhafi FN, Coop MR, Georgiannou VN (2016) Effect of particle shape on the mechanical behavior of natural sands. J Geotech Geoenviron Eng 142(12):04016071

4. Bolton MD (2000) The role of micro-mechanics in soil mechanics. In: Proceedings of the international workshop on soil crushability. Yamaguchi University, Japan

5. Bolton MD, Mcdowell GR (1997) Clastic mechanics. lutam symposium on mechanics of granular and porous materials. Dordrecht, Kluwer Academic Publishers

6. Carrera A, Coop M, Lancellotta R (2011) Influence of grading on the mechanical behaviour of stava tailings. Géotechnique 61(11):935-946

7. Cavarretta I, Coop M, O'sullivan C (2010) The influence of particle characteristics on the behaviour of coarse grained soils. Geotechnique 60(6):413-423

8. Chandler R, Tosatti G (1995) The stava tailings dams failure, Italy, July 1985. Proc ICE-Geotech Eng 113(2):67-79

9. Chang HPN (2011) The effect of fabric on the behaviour of gold tailings. Géotechnique 61(3):187-197

10. Cheng YPH, Nakata Y, Bolton M (2003) Discrete element simulation of crushable soil. Geotechnique 53(7):633-641

11. Cho G, Dodds J, Santamarina J (2006) Particle shape effects on packing density, stiffness, and strength: natural and crushed sands. J Geotech Geoenviron Eng 132(5):591-602

12. Coop M, Atkinson J (1993) The mechanics of cemented carbonate sands. Geotechnique 43(1):53-67

13. Coop MR (1990) The mechanics of uncemented carbonate sands. Géotechnique 40(4):607-626

14. Daouadji A, Hicher PY, Rahma A (2001) An elastoplastic model for granular materials taking into account grain breakage. Eur J Mech 20(1):113-137 
15. Donohue S, O'sullivan C, Long M (2016) Particle breakage during cyclic triaxial loading of a carbonate sand. Géotechnique 59(5):477-482

16. Einav I (2007) Breakage mechanics — part I: theory. J Mech Phys Solids 55(6):1274-1297

17. Einav I (2007) Breakage mechanics_-part ll: modelling granular materials. J Mech Phys Solids 55(6):1298-1320

18. Hardin B (1985) Crushing of soil particles. J Geotech Eng 111(10):1177-1192

19. Liu X, Yang J, Wang G, Chen L (2016) Small-strain shear modulus of volcanic granular soil: an experimental investigation. Soil Dyn Earthquake Eng 86:15-24

20. Mcdowell GR (2002) On the yielding and plastic compression of sand. J Jpn Geotech Soc Soils Found 42(1):139-145

21. Mcdowell GR (2003) Micromechanics of creep of granular materials. Géotechnique 53(10):915-916

22. Mcdowell GR, Amon A (2000) The application of Weibull statistics to the fracture of soil particles. Soils Found 40(5):133-141

23. Mcdowell GR, Bolton MD (1998) On the micromechanics of crushable aggregates. Géotechnique 48(5):667-679

24. Mcdowell GR, Bolton MD, Robertson D (1996) The fractal crushing of granular materials. J Mech Phys Solids 44(12):2079-2101

25. Mcdowell GR, De Bono JP (2013) On the micro mechanics of one-dimensional normal compression. Géotechnique 63(11):895-908

26. Minh N, Cheng Y (2012) Strong force network of granular mixtures under one-dimensional compression. Discrete element modelling of particulate media. RSC Publishing, Cambridge

27. Mitchell J, Soga K (2005) Fundamentals of soil behaviour. Wiley, New York

28. Muir Wood D (2007) The magic of sands. Can Geotech J 44(11):1329-1350

29. Nakata Y, Hyodo M, Hyde AFL, Kato Y, Murata H (2001) Microscopic particle crushing of sand subjected to high pressure one-dimensional compression. J Jpn Geotech Soc Soils Found 41(1):62-82

30. Nakata Y, Kato Y, Hyodo M, Murata H. Single particle crushing properties of geomaterials In: Jamiolkowski MB, Lancellotta R, Lo Presti D (eds). International symposium on pre-failure deformation characteristics of geomaterials 1999 Torino, Italy. Rotterdam: A.A. Balkema

31. Nardelli V, Coop MR (2016) The micromechanical behaviour of a biogenic carbonate sand. Procedia Eng 158:39-44

32. Pender M, Wesley L, Larkin T, Pranjoto S (2006) Geotechnical properties of a pumice sand. Soils Found 46(1):69-81

33. Rousé PC, Fannin RJ, Shuttle DA (2008) Influence of roundness on the void ratio and strength of uniform sand. Géotechnique 58(3):227-231

34. Russell AR (2011) A compression line for soils with evolving particle and pore size distributions due to particle crushing. Géotech Lett 1(January-March):5-9

35. Shi Y, Yan WM, Mukunoki T, Sato T, Otani J (2015) A microscopic investigation into the breakage behavior of calcareous origin grains in 1d compression. Jpn Geotech Soc Spec Publ 2(16):630-634

36. Wadell H (1932) Volume, shape, and roundness of rock particles. J Geol 40:443-451

37. Weibull W (1951) A statistical distribution function of wide applicability. J Appl Mech 13:293-297

38. Xiao Y, Liu H, Chen Q, Ma Q, Xiang Y, Zheng Y (2017) Particle breakage and deformation of carbonate sands with wide range of densities during compression loading process. Acta Geotech 12:1-8

39. Zhang XY, Baudet BA (2013) Particle breakage in gap-graded soil. Géotech Lett 3(2):72-77

40. Zhang XY, Baudet BA, Coop M (2016) An investigation of particle breakage at elecated pore pressures using a simple new oedometer. Soils Found (under review)

41. Zhao BD, Wang J, Coop MR, Viggiani C, Jiang MJ (2015) An investigation of the single sand particle fracture using X-ray micro-tomography. Géotechnique 65(8):625-641

\section{Publisher's Note}

Springer Nature remains neutral with regard to jurisdictional claims in published maps and institutional affiliations.

\section{Submit your manuscript to a SpringerOpen ${ }^{\circ}$ journal and benefit from:}

- Convenient online submission

- Rigorous peer review

- Open access: articles freely available online

- High visibility within the field

- Retaining the copyright to your article

Submit your next manuscript at $\boldsymbol{\nabla}$ springeropen.com 